\title{
Detection of thermophilic Campylobacter sp. in raw chicken sausages by methods ISO 10272: 2006 in Curitiba - Parana State - Brazil
}

\author{
K. Konell ${ }^{1}$, M.A. Gelinsk ${ }^{1}$, T.M. Benetti ${ }^{2}$, W.M. Abrahão ${ }^{1,3}$ \\ ${ }^{1}$ Departamento de Farmácia, Universidade Federal do Paraná, Curitiba, PR, Brazil. \\ ${ }^{2}$ Departamento de Ciência e Tecnologia de Alimentos, Universidade Estadual de Londrina, \\ Londrina, PR, Brazil. \\ ${ }^{3}$ Secção de Microbiologia de Alimentos, Laboratório Central do Estado do Paraná, Curitiba, PR, Brazil.
}

Submitted: July 22, 2012; Approved: June 6, 2014.

\begin{abstract}
The aim of this study was the detection of Campylobacter sp. in raw chicken sausages using the methods ISO 10272-1 and ISO 10272-2. The overall prevalence of Campylobacter sp. in the samples tested was $16.67 \%$, representing a serious risk to the health of consumers, particularly if measures guaranteeing proper cooking of foods and prevention of cross-contamination are not adopted. Furthermore, the majority of campylobacteriosis cases in humans are caused by consumption or improper handling of contaminated raw or undercooked poultry meat, which constitute the main vehicle of this infection.
\end{abstract}

Key words: Campylobacter sp., poultry meat, chicken sausages.

Campylobacter jejuni and Campylobacter coli are the leading bacterial cause of gastroenteritis in humans worldwide. Infected humans can manifest a series of clinical symptoms ranging from mild watery diarrhea to severe inflammation (Humphrey et al., 2007). Moreover, C. jejuni has been identified as a major infectious agent in GuillainBarre syndrome, a disease affecting the peripheral nervous system that causes neuron demyelination (Godschalk et al., 2004). The majority of campylobacteriosis cases in humans is sporadic and caused by consumption or improper handling of contaminated raw or undercooked poultry meat, which constitute the main vehicle of infection (EFSA, 2009).

Brazil is a world leader in the production and processing of poultry meat, production in 2012 was $12,645,000$ tons. The state of Paraná is considered the biggest producer of broilers in Brazil, contributing with $28.0 \%$ of the production (IBGE, 2013). The prevailing Brazilian legislation (Brazil, 2001) does not regulate for Campylobacter contamination in foodstuffs. Although Brazil is a major exporter of poultry meat, scant information is available on the contamination of these products and subproducts by Campylobacter.
Refrigerated sausages are regarded as a food with high exposure to contamination given the intense manipulation inherent to their manufacturing process, where the presence of these micro-organisms suggests contamination during meat processing (Barros et al., 2007).

The aim of the present study was the detection of Campylobacter sp. in raw chicken sausages using the methods ISO 10272-2: 2006 (colony-count technique) and ISO 10272-1: 2006 (detection method). The sausages assessed were commercially available from markets in Curitiba city, Paraná State, Brazil. A further analysis was carried out comparing the two methods for the detection of Campylobacter sp.

A total of 30 samples of raw chicken sausages were purchased from different commercial outlets in the municipality of Curitiba - Paraná State, both in pre-packed and loose-weighed form, over the period spanning from November to December 2011. The minimum amount of $200 \mathrm{~g}$ was acquired for each sample to ensure representativity as recommended by RDC (Board of Commerce Resolution) No. 12 of 02/01/2001 of ANVISA/MS (National Health Surveillance Agency/Health Ministry) (Brazil, 2001). After collection, samples were sent to the laboratory under re- 
frigerated storage. For dilution, portions of $5 \mathrm{~g}$ from each sample were taken for analysis and placed into adapted flasks (7) containing $45 \mathrm{~mL}$ of Bolton broth supplemented with cefoperazone $(10.0 \mathrm{mg})$, vancomycin $(10.0 \mathrm{mg})$, trimethoprim $(10.0 \mathrm{mg})$ and amphotericin B (5.0 mg) (SR 208E) (volume corresponding to $500 \mathrm{~mL}$ of medium) (Oxoid, England).

For the colony-count technique (ISO10272-2: 2006), aliquots of $0.1 \mathrm{~mL}$ of the mixture (sample + Bolton broth) were streaked onto plates containing modified Charcoal Cefoperazone Deoxycholate Agar (mCCDA) (CM 739) (Oxoid, England) supplemented with cefoperazone (16.0 mg) and amphotericin B (5.0 mg) (SR 155E) (volume corresponding to $500 \mathrm{~mL}$ of medium) (Oxoid, England) and Modified Bolton Agar (MBA) in duplicate. The MBA was prepared from the Bolton broth (CM 983) (Oxoid, England) with agar-agar $(1.5 \%)$, ferrous sulphate $(0.5 \mathrm{~g} / \mathrm{L})$ (Carlo Erba) and 2,3,5-triphenyltetrazolium chloride solution (TTC) (200 ppm) (Merck). Thereafter, a selective supplement with cefoperazone (10 mg), trimethoprim (10 mg), vancomycin $(10 \mathrm{mg})$ and cycloheximide $(25 \mathrm{mg})$ was added (SR 183E) (volume corresponding to $500 \mathrm{~mL}$ of medium) (Oxoid, England). Plates were incubated (41.5 $\pm 0.5){ }^{\circ} \mathrm{C}$ for $48 \mathrm{~h}$ in a microaerophilic atmosphere developed by an injection system $\left(5 \% \mathrm{O}_{2}, 10 \% \mathrm{CO}_{2}, 85 \% \mathrm{~N}_{2}\right)$ (Air Liquide) for $20 \mathrm{~s}$. MBA and the microaerophilic injection system were prepared as described by Franchin et al. (2005).

Five typical colonies from each plate were observed under a microscope in freshly prepared samples stained with $1 \%$ methylene blue solution (Laborclin, Brasil), and gram stain (Laborclin, Brasil). The typical colonies exhibiting characteristic morphology were reisolated onto Tryptic Soy Agar (TSA) supplemented with 5\% defibrinated sheep blood (Newprov, Brasil), and incubated $(36 \pm 1){ }^{\circ} \mathrm{C}$ for 24 and $48 \mathrm{~h}$ in a microaerophilic atmosphere. Identification was performed by biochemical tests: catalase, oxidase, hippurate hydrolysis, indoxyl acetate; and evaluated the sensibility to nalidixic acid and cephalotihn. In addition to the biochemical tests was performed identification employing the API CAM ${ }^{\circledR}$ system (Biomerieux, France) according to manufacturer's directions.

For the detection method (ISO 10272-2: 2006), the prepared mixture containing $5 \mathrm{~g}$ of sample and $45 \mathrm{~mL}$ of Bolton broth was incubated $(37){ }^{\circ} \mathrm{C}$ for $4 \mathrm{~h}$ and subsequently incubated $(41.5 \pm 0.5){ }^{\circ} \mathrm{C}$ for $48 \mathrm{~h}$, under microaerophilic injection (Air Liquide, Brazil) for $10 \mathrm{~s}$. The enriched mixture was plated on $\mathrm{mCCDA}$ and MBA, and then incubated $(415 \pm 0.5){ }^{\circ} \mathrm{C}$ for $48 \mathrm{~h}$ under a microaerophilic atmosphere. Typical Campylobacter colonies were identified using the procedure outlined in method ISO 10272-2 (2006).

The prevalence of Campylobacter sp., and analysis of the detection methods were compared with the use of global percentage of agreement accuracy and the proportion of true results (Hong Kong University on line statistical package) (Hong Kong University, 2013) and Z-test for two proportion of independent samples (Epi Tools on line statistical package) (Epi Tools, 2013). Significance was set at $\mathrm{p}<0.05$ for the null hypothesis.

Based on the results of the two analysis methodologies, the prevalence of Campylobacter sp. in the samples was $16.67 \%$, of which $13.33 \%$ represented Campylobacter jejuni subsp doylei, and 3.34\% for Campylobacter lari.

This study yielded $03(10.00 \%)$ positive samples by the colony-count technique, and $02(6.67 \%)$ by the detection method. Positive results were found by one or another method, with none of the samples testing positive on both methods $( \pm)$. It was figured $90.0 \%$ of global concordance for colony count technique and $100 \%$ for detection method. Detection method did not show any discordance either positive or negative (Table 2).

Three samples (samples 12, 15 and 22) identified by direct plating but not isolated after enrichment, suggest this event was due to the presence of a microbiota contaminant not inhibited by the mix of antibiotics in the Bolton broth. This microbiota contaminant thus inhibited the growth of the viable Campylobacter population.

However, two samples (samples 17 and 23) identified only upon enrichment may be explained by them having a low concentration of Campylobacter or a non-viable population, thus precluding detection at the direct plating stage yet allowing recovery after enrichment.

Taken together, the results found for both methodologies tested highlight the importance of concomitant use of the two methods given the micro-organism is both fastidious and difficult to culture from food samples.

The results in Table 1 indicate 4 positive values $(13.34 \%)$ for MBA, and only $3(10.0 \%)$ for mCCDA. Thus, MBA shows a superior performance, although without statistical significance ( $Z$ test, $p=0.687$ ). The ISO standard stipulates the use of mCCDA and recommends a complementary selective medium at the discretion of the analyst.

Ferreira et al. (2007), in a study adopting the method ISO 10272-1, failed to detect Campylobacter sp. in samples of alheiras, traditional sausages from Northern Portugal. In

Table 1 - Positive results identified by colony-count technique and detection method.

\begin{tabular}{lcccccc}
\hline & \multicolumn{2}{c}{$\begin{array}{c}\text { Colony-count } \\
\text { technique }\end{array}$} & & \multicolumn{2}{c}{$\begin{array}{c}\text { Detection } \\
\text { method }\end{array}$} \\
\cline { 2 - 3 } \cline { 5 - 6 } Sample & mCCDA & MBA & & mCCDA & MBA \\
\hline 12 & - & + & & - & - \\
15 & - & + & & & - & - \\
17 & - & - & & + & + \\
22 & + & - & & - & - \\
23 & - & - & & & + & + \\
\hline
\end{tabular}


Table 2 - Concordance analyses of selective media for the two methods used for Campylobacter detection.

\begin{tabular}{lcc}
\hline & $\begin{array}{c}\text { Colony count } \\
\text { technique }\end{array}$ & $\begin{array}{c}\text { Detection } \\
\text { method }\end{array}$ \\
\hline Positive concordance & 0 & 2 \\
Positive discordance & 1 & 0 \\
Negative discordance & 2 & 0 \\
Negative concordance & 27 & 28 \\
$\begin{array}{l}\text { Global percentage of } \\
\text { concordance }\end{array}$ & $90.00 \%$ & $100.00 \%$ \\
\hline
\end{tabular}

Selective media used were mCCDA and MBA.

addition, the authors attributed the absence of pathogens to the smoking process used to cure the sausages.

Similarly, Cortez et al. (2004) detected no Campylobacter in their analysis of 106 sausage samples. The authors hold that Campylobacter is sensitive to factors intrinsic to sausage production, such as the addition of sodium chloride and spices.

Therefore, it is clear that the detection level of Campylobacter sp. in $16.67 \%$ of chicken sausage sample assessed in this study is significant comparing to the no pathogen isolation by Cortez et al. (2004); although this study have used a different protocol for the isolation.

The results of this study showed that factors intrinsic to the production of sausages for human consumption were unable to inhibit Campylobacter growth in the samples tested.

These findings suggest that refrigeration during storage and sale of the product did not hamper recovery of Campylobacter. These results corroborate the observations of Maziero and Oliveira (2010), who reported no significant difference in the prevalence of $C$. jejuni between fresh samples and those stored at low temperatures, indicating that the organism is able to survive under frozen storage conditions.

Nevertheless, the source of potential contamination of our samples could not be established. Since the samples were purchased in loose-weighed and pre-packed form, cross-contamination may have taken place at the commercial outlets from other poultry subproducts through contaminated equipment and work surfaces.

Concerned with this scenario, Burgess et al. (2005) assessed the external packaging of raw poultry meat and confirmed the presence of Campylobacter on $1.1 \%$ of items, pointing to the need for rigorous care in the handling of foodstuffs and their contact with surfaces, as well as the cleaning of utensils, equipment and exposed surfaces.

Overall, the isolation of Campylobacter in the raw chicken sausage samples tested indicates that good hygiene practices are not being adhered to during the processing, storage and distribution stages, representing basic measures for the prevention of contaminants, whose absence poses a safety hazard for human consumption of the product.

To conclude, considering that we dealt with raw product, the presence of Campylobacter sp. in $16.67 \%$ samples, poses a serious threat to public health, since it suggests that measures for guarantee of proper cooking of foods and prevention of cross-contamination were not. Since data was obtained under a pilot experiment further studies must be conducted to understand the behavior of Campylobacter in raw chicken sausages, and thus to reduce the contamination possibility.

\section{Acknowledgments}

We thank the Federal University of Paraná, the Central Laboratory of the State of Paraná and the State University of Londrina for supporting this study.

\section{References}

Barros MAF, Nero LA, Monteiro AA, Beloti V (2007) Identification of main contamination points by hygiene indicator microorganisms in beef processing plants. Food Sci Technol 27:856-862.

Brazil. National Agency for Sanitary Vigilance (2001) RDC Resolution No. 12, dated January 2, 2001. Technical Regulation on microbiological standards for foods. ANVISA - National Agency for Sanitary Vigilance. Official Gazette Executive, Section I.

Burgess F, Little CL, Allen G, Williamson K, Mitchell RT (2005) Prevalence of Campylobacter, Salmonella, and Escherichia coli on the external packaging of raw meat. J Food Prot 68:469-475.

Cortez ALL, Carvalho ACFB, Amaral LA, Salotti BM, Vidal-Martins AMC.(2004) Fecal coliforms, coagulase positive staphylococci (CPS), Salmonella spp. and Campylobacter spp. in fresh sausages. Alim Nutr 15:215-220.

EFSA, European Food Safety Authority. 2009. EFSA's 12th Scientific Opinion on Quantification of the risk posed by broiler meat to human campylobacteriosis in the EU. Available in: http://www.efsa.europa.eu/en/efsajournal/doc/1437.pdf Acess in july 2013.

Epi Tools Estatistic on line (2013). Available in: http://epitools.ausvet.com.au Acess in july 2013.

Ferreira V, Barbosa J, Silva j, Felicio M, Mena C, Hoog T, Gibbs P, Teixeira P. (2007). Characterisation of alheiras, tradicional sausages produced in the North of Portugal, with respect to their microbiological safety. Food Control 18:436-440.

Franchin PR, Aidoo KE, Batista CRV (2005) Sources of poultry meat contamination with thermophilic Campylobacter before slaughter. Braz J Microbiol 6:157-162.

Godschalk PC, Heikema AP, Gilbert M, Komagamine T, Ang CW, Glerum J, Brochu D, Li J, Yuki N, Jacobs BC, Van Belkum A, Endtz HP (2004) The crucial role of Campylobacter jejuni genes in anti-ganglioside antibody induction in Guillain-Barre syndrome. J Clin Invest 114:1659-1665. 
Hong Kong University Estatistic on line (2013). Available in: http://depart-

ment.obg.cuhk.edu.hk/researchsupport/SenSpc.asp Acess in july 2013.

Humphrey T, O’Brien S, Madsen M (2007). Campylobacters as zoonotic pathogens: a food production perspective. Int $\mathrm{J}$ Food Microbiol 117:237-257.

IBGE. Instituto Brasileiro de Geografia e Estatística (2013) Available in: http://www.ibge.gov.br/home/estatistica/indicadores/agrop ecuaria/producaoagropecuaria/abate-leite-couro-ovos_201 204_publ_completa.pdf Access in july 2013.
ISO. International Organization for Standardization (2006) ISO 10272 Microbiology of Food and Animal Feeding Stuff Horizontal Method for Detection and Enumeration of Campylobacter spp. - Part 1: Enrichment Method; Part 2: Enumeration Method. ISO, Geneva, Switzerland.

Maziero MT, Oliveira TCRM (2010) Effect of refrigeration and frozen storage on the Campylobacter jejuni recovery from naturally contaminated broilerskins. Braz J Microbiol 41:501-505.

All the content of the journal, except where otherwise noted, is licensed under a Creative Commons License CC BY-NC. 